\title{
Reassessing coral U-Th dating
}

\author{
A.TRINQUIER ${ }^{1}$, G.BAYON $^{1}$, E.EDINGER $^{2}$, S.JORRY $^{1}$
}

${ }^{1}$ IFREMER, Marine Geosciences Unit, Plouzané, France

(anne.trinquier@ifremer.fr, germain.bayon@ifremer.fr, stephan.jorry@ifremer.fr)

${ }^{2}$ Memorial University, St. John's, NL, A1B 3X9 Canada

(eedinger@mun.ca)

Coral carbonate skeletons constitute paleoceanographic archives of rapid responses in ocean temperature, chemistry and circulation, to climatic, tectonic and seismic events. ${ }^{238} \mathrm{U}-$ ${ }^{234} \mathrm{U}-{ }^{230} \mathrm{Th}$ dating of corals can yield an absolute chronology of past environmental changes over the time period of about 1 to 600 kyrs before present, and concomittantly underly the calibration of radiocarbon time scales, as well as the use of ${ }^{14} \mathrm{C}$ as a water-mass proxy [1]. However, multiple sources of potential bias related to sampling, analytical protocols and uncertainty propagation require thorough inspection prior to validating U-Th ages, such as (i) pristinity and purity of coralline aragonite (ii) contamination related to the presence of initial detrital and/or hydrogenous ${ }^{230} \mathrm{Th}$ (iii) limited counting statistics and detector intercalibration (iv) peak tailing and hydride interference corrections (v) choice of well-constrained carbonate references for accurate age uncertainty assessment.

We aim at proposing an accurate U-Th dating protocol for corals of deep-sea environments that suffered mild Fe-Mn crust contaminations, by circumventing analytical challenges and Fe-Mn crust remains.

We applied our protocol to the dating of coralline aragonite from the Mayotte, Glorieuses and Comores areas, which are subject to volcanism and thus prone to $\mathrm{Fe}-\mathrm{Mn}$ oxide contaminations.

[1] Edwards et al. (2003). Reviews in Mineralogy and Geochemistry 52, 363-405. 